БЛАГИНИН Владислав Сергеевич - научный сотрудник Липецкого филиала Финансового университета при Правительстве РФ (398050, Россия, г. Липецк, ул. Интернациональная, 12б; kibervlad@ mail.ru)

ЛИНЧЕНКО Андрей Александрович - кандидат философских наук, доцент; научный сотрудник Липецкого филиала Финансового университета при Правительстве РФ (398050, Россия, г. Липецк, ул. Интернациональная, 12б; linchenko1@таil.ru)

ГОЛОВАШИНА Оксана Владимировна - кандидат исторических наук, доцент Тамбовского государственного университета им. Г.Р. Державина (392000, Россия, г. Тамбов, ул. Интернациональная, 33, ovgolovashina@mail.ru)

\title{
ПРАЗДНИЧНЫЕ КОММЕМОРАЦИИ И СИМВОЛИЧЕСКИЕ ДАТЫ В СОВРЕМЕННОМ РОССИЙСКОМ МИГРАЦИОННОМ ОБЩЕСТВЕ
}

\begin{abstract}
Аннотация. В статье анализируются результаты эмпирического исследования, проведенного в Саратове, Липецке, Тамбове, Воронеже, Казани. Цель работы состояла в изучении возможностей интеграции культурной памяти мигрантов в российское общество на примере коммеморативных практик, связанных с праздничной культурой. Авторы понимают праздник как индикатор и инструмент культурноисторического обмена. На основе теоретико-методологической рамки анализ эмпирического материала показал следующие результаты: 1) мигранты в целом положительно оценивают российские праздники, но только треть из них принимают в праздничных практиках активное участие; 2) с возрастом и увеличением длительности проживания мигранты находят больше возможностей для отмечания религиозных праздников; 3) большинство мигрантов соблюдают светские и религиозные обычаи страны исхода.
\end{abstract}

Ключевые слова: мигранты, культурная память, праздничные коммеморации, интеграция

$\mathrm{H}$ есмотря на то что миграционные процессы давно уже являются привычной стороной социально-экономической и политической жизни, проблемы взаимодействия культурной памяти мигрантов и принимающего общества лишь недавно стали предметом исследовательского интереса за рубежом [Memory and Migration... 2011; Holocaust Memory... 2017; History, Memory... 2012; Perceptions of the Holocaust... 2013]. Парадоксально, но при всем многообразии работ, направленных на изучение социокультурной адаптации и интеграции мигрантов в России, обращает на себя внимание незначительное число исследований, посвященных проблемам интеграции культурной памяти мигрантов в российское общество [Авдеева 2018; Шумилова 2018]. Не будет преувеличением заметить, что наиболее продуктивный путь изучения процессов взаимодействия культурной памяти мигрантов и принимающего общества лежит в сфере исследования практического взаимодействия. Это связано с тем, что миграция является не только социальным процессом, но и прежде всего трансформацией индивидуального человеческого опыта, более или менее успешной адаптацией в новой социально-психологической и культурной среде. С этой точки зрения праздничная культура занимает далеко не последнее место в ряду практик, служащих одновременно и инструментом, и индикатором культурноисторического обмена.

Одной из лучших дефиниций праздника, данных в рамках актуальной сегодня конструктивистской методологии, является определение Пьера Бурдье, который интерпретировал праздник как набор устойчивых ритуализированных социальных и политических практик, которые призваны обеспечивать «консенсус людей по поводу смысла социального мира» [Бурдье 2007: 92]. Данное 
определение позволяет сделать шаг навстречу современным исследованиям культурной памяти. На основе феноменологической трактовки культуры как результата познавательного опыта, конструирующего социальную реальность в ходе повседневных практик, культурная память рассматривается в качестве совокупности разделяемых и конструируемых представлений о временных, политических, социокультурных аспектах истории народа, выступающих инструментом формирования и поддержания групповой идентичности. Культурная память является многокомпонентным продуктом коллективного сознания, включающим в себя ряд аксиологических, когнитивных и поведенческих аспектов, каждый из которых позволяет говорить о специфических измерениях праздничной коммеморации.

В настоящее время под влиянием глобализационных процессов, развития межкультурного взаимовлияния и взаимодействия представителей различных культур особо остро стоит вопрос социальных коммемораций. Не избежала его и Россия, которая, по оценкам видных российских социологов (В.И. Мукомель, А.В. Дмитриев, В.С. Малахов, М. Мкртчян), давно уже является иммиграционной страной. Взаимопроникновение культурных форм, образцов, моделей поведения и мировоззренческих установок осушествляется посредством процесса культурной диффузии, являющейся результатом культурного контактирования, осуществляемого через различные диффузионные каналы. Это связано с тем, что взаимодействие компонентов культуры, происходящее во время пребывания мигрантов в принимающей стране, является многофакторным феноменом, охватывающим множество сфер общественной жизни. Взаимопроникновение культур формирует особенности коммуникации между коренным населением и мигрантами, а также мировоззренческие установки и ценности обеих социальных групп, которые, в конечном итоге, влияют на сознание и поведение как отдельных групп индивидов, так и общества в целом. Миграционные потоки приводят к тому, что представители различных сообеест перемешиваются друг с другом, сохраняя и даже гипертрофированно воспроизводя коммеморативные практики, свойственные их изначальному месту пребывания. В такой ситуации анализ исторических праздников в условиях функционирования миграционных сообществ становится способом выявления культурных противоречий и нахождения механизмов установления межкультурного взаимодействия.

Изучение праздничных коммемораций и символических дат является важным инструментом для осмысления свойств и особенностей культурной памяти населения России, выявления общественного настроения, уровня социальной напряженности и возможных способов взаимодействия коренного населения и мигрантов. Исследование вопросов культурной диффузии праздничных коммемораций являлось одним из блоков масштабного социологического исследования, реализованного коллективом проекта весной 2018 г. при поддержке Российского научного фонда. Исследование проводилось среди мигрантов и принимающего сообщества методами анкетирования и глубинного интервью.

В предлагаемой статье представлены результаты анализа 3003 анкет респондентов, постоянно проживающих в городах Тамбове, Липецке, Воронеже, Саратове, Казани. Выборка квотная (многоступенчатая). Квотами являются город проживания, пол и возраст респондента. Для анализа результатов использовано частотное распределение ответов, а также таблицы сопряженности. Одновременно с исследованием «коренного» населения в этих городах проводился опрос мигрантов $(N=300)$. Для получения качественной информации в 2019 г. было дополнительно проведено 156 интервью с мигрантами, проживающими в этих городах более 3 лет. Интервью проводились на русском языке. Одним из блоков исследования стало изучение праздничных коммемораций. 
Нами был проведен анализ мнения коренных жителей об иностранных праздниках и мнения мигрантов по отношению к праздникам коренного населения (как к иностранным праздникам).

Результаты исследования показывают, что, несмотря на довольно либеральное отношение к собственной культуре с точки зрения ее лингвистических аспектов, отношение россиян к иностранным праздникам, в частности к западным, можно охарактеризовать как консервативное. Лишь 19,3\% респондентов считают нормой праздновать иностранные праздники. Положительно относятся к праздникам, завоевавшим определенную популярность у населения, таким как, например, День святого Валентина или Хэллоуин, 33,7\% коренного населения. Большинство же респондентов (47\%) отрицательно относятся к западным праздникам. Данные тенденции вполне объяснимы на фоне устойчивого роста ксенофобии в нашей стране в последние годы, зафиксированного социологическими опросами. Характерно, что вектор этих настроений практически не меняется и, как и прежде, направлен на выходцев с Кавказа, из Закавказья, а также республик Средней Азии [Дмитриев, Мукомель 2008: 105; Воронова, Воронов 2019: 75].

Отношение мигрантов к российским праздникам в целом можно охарактеризовать как положительное. $36,1 \%$ респондентов разделяют отношение местного населения к праздникам и принимают в них участие. Примерно такая же часть респондентов (32\%) принимает местные праздники, но не празднует их. Отсутствие негативного отношения к местным праздникам также может характеризовать нейтральная оценка мигрантами местных праздников $(25,6 \%$ общего числа опрошенных). Лишь $6,4 \%$ респондентов не принимают праздники коренного населения. В этой связи заметим, что открытость трудовых мигрантов по отношению к российским праздникам и готовность принимать в них участие была выявлена и в исследованиях 2016 (Екатеринбург) [Шумилова 2018: 401], а также 2018 (Красноярск) годов [Авдеева 2018: 139].

Анализ отношения мигрантов к праздникам коренного населения в разрезе возраста показывает, что наиболее лояльны к местным праздникам мигранты из стран бывшего Советского Союза старше 50 лет. Это та категория, которая росла и воспитывалась в едином социокультурном пространстве СССР. В интервью эта категория граждан чаще всего упоминала празднование Дня Победы, Нового года, Праздника весны и труда. Религиозные праздники этой категорией граждан не упоминались. Наиболее нейтральны к праздникам коренного населения мигранты в возрасте до 24 лет (см. табл. 1). Анализ интервью показал, что из праздничных практик мигрантов практически полностью уходят военные коммеморации, но сохраняется внимание к историческим деятелям и значимым событиям истории России.

Таблица 1

\section{Отношение мигрантов к праздникам принимающего общества в зависимости от возраста, \%}

\begin{tabular}{|c|c|c|c|c|c|c|}
\hline \multirow{2}{*}{$\begin{array}{c}\text { Как Вы относитесь } \\
\text { к местным праздникам? }\end{array}$} & \multicolumn{6}{|c|}{ Возраст респондента, годы } \\
\hline & $18-24$ & $25-29$ & $30-39$ & $40-49$ & $50-59$ & 60 и старше \\
\hline $\begin{array}{l}\text { Не принимаю местные } \\
\text { праздники }\end{array}$ & 25,0 & - & - & 25,0 & - & - \\
\hline Отношусь нейтрально & 75,0 & 40,0 & 6,3 & 50,0 & - & - \\
\hline $\begin{array}{l}\text { Принимаю, но не праздную } \\
\text { местные праздники }\end{array}$ & - & 10,0 & 12,5 & 25,0 & - & - \\
\hline $\begin{array}{l}\text { Принимаю и праздную местные } \\
\text { праздники }\end{array}$ & - & 50,0 & 81,3 & - & 100,0 & 100,0 \\
\hline
\end{tabular}


Если анализировать ответы на вопрос в разрезе продолжительности проживания, то выделяется категория мигрантов, проживающих в городах опроса менее 1 года: в их ответах нет нейтральности. Большинство из них (80\%) принимают и празднуют местные праздники. Не принимают местные праздники $20 \%$ (см. табл. 2). Это объясняется необходимостью хотя бы поверхностного знакомства с культурой принимающего общества, как правило, возникающей в ходе контактов в рамках трудовой деятельности. При этом показательно, что по мере увеличения длительности проживания данная заинтересованность падает и актуализируется лишь у тех, кто прожил в России более 11 лет.

Таблица 2

\section{Отношение мигрантов к местным праздникам в зависимости от длительности проживания в принимающем обществе, \%}

\begin{tabular}{|l|c|c|c|c|c|}
\hline \multirow{2}{*}{$\begin{array}{c}\text { Как Вы относитесь } \\
\text { к местным праздникам? }\end{array}$} & \multicolumn{6}{|c|}{ Длительность проживания на территории города, } \\
\cline { 2 - 6 } & Менее 1 & $\mathbf{1 - 2}$ & $\mathbf{3 - 5}$ & $\mathbf{6 - 1 0}$ & $\mathbf{1 1 - 2 0}$ \\
\hline Не принимаю местные праздники & 20,0 & - & - & 8,3 & - \\
\hline Отношусь нейтрально & - & 40,0 & 38,5 & 25,0 & - \\
\hline $\begin{array}{l}\text { Принимаю, но не праздную местные } \\
\text { Праздники }\end{array}$ & - & - & 15,4 & - & 100,0 \\
\hline $\begin{array}{l}\text { Принимаю и праздную местные } \\
\text { Праздники }\end{array}$ & 80,0 & 60,0 & 46,2 & 66,7 & - \\
\hline
\end{tabular}

Россияне, как и мигранты, в равной степени отмечают и светские, и церковные праздники (характерные для своей социокультурной общности). В вопросе соблюдения праздничных традиций своей культуры между мигрантами и местным населением российских городов отличие наблюдается лишь в числе людей, придерживающихся светских взглядов (30,4\% опрошенных россиян против $19,6 \%$ мигрантов). Исключительно церковные праздники соблюдают лишь $6,5 \%$ россиян (против $12,8 \%$ у мигрантов). При этом мигранты положительно оценивают культурную инфраструктуру российских городов. Подавляющее большинство опрошенных мигрантов $(82,1 \%)$ отметили наличие условий для проведения религиозных обрядов и праздников. Анализ ответов в зависимости от возраста показывает, что с возрастом мигранты находят больше возможностей для проведения религиозных обрядов и праздников (см. табл. 3).

Таблица 3

\section{Оценка мигрантами условий для проведения религиозных мероприятий в зависимости от возраста, \%}

\begin{tabular}{|l|c|c|c|c|c|c|}
\hline \multirow{2}{*}{$\begin{array}{c}\text { Имеются ли у Вас в данном городе } \\
\text { условия для проведения религиозных }\end{array}$} & \multicolumn{5}{|c|}{ Возраст респондента, годы } \\
\cline { 2 - 7 } \begin{tabular}{c} 
обрядов и праздников? \\
\cline { 2 - 7 }
\end{tabular} & $\mathbf{1 8 - 2 4}$ & $\mathbf{2 5 - 2 9}$ & $\mathbf{3 0 - 3 9}$ & $\mathbf{4 0 - 4 9}$ & $\mathbf{5 0 - 5 9}$ & $\begin{array}{c}\mathbf{6 0} \text { и } \\
\text { старше }\end{array}$ \\
\hline Нет & 75,0 & 40,0 & 31,3 & 25,0 & - & - \\
\hline Да & 25,0 & 60,0 & 68,8 & 50,0 & 100,0 & 100,0 \\
\hline
\end{tabular}

Аналогичная тенденция наблюдается при увеличении длительности проживания на территории города (см. табл. 4). Чем дольше мигранты проживают на территории, тем больше они находят возможностей для проведения своих 
религиозных обрядов и праздников. Среди религиозных праздников мигранты мусульманского вероисповедания отмечают 2 главных праздника: Уразабайрам и Курбан-байрам. Мигранты христианского вероисповедания упоминают Рождество и Пасху. Данный факт уже неоднократно отмечался исследователями [Авдеева 2018: 140; Шумилова 2018: 400].

Таблица 4

\section{Оценка мигрантами условий для проведения религиозных мероприятий в зависимости от длительности проживания, \%}

\begin{tabular}{|c|c|c|c|c|c|}
\hline \multirow{2}{*}{$\begin{array}{c}\text { Имеются ли у Вас в данном городе } \\
\text { условия для проведения религиозных обрядов } \\
\text { и праздников? }\end{array}$} & \multicolumn{5}{|c|}{$\begin{array}{c}\text { Длительность проживания на территории } \\
\text { города, полных лет } \\
\end{array}$} \\
\hline & Менее 1 & $1-2$ & $3-5$ & $6-10$ & $11-20$ \\
\hline Нет & 65,0 & 60,0 & 46,2 & 33,3 & - \\
\hline Да & 35,0 & 40,0 & 53,8 & 66,7 & 100,0 \\
\hline
\end{tabular}

Во многом благодаря наличию инфраструктуры для проведения праздников среди мигрантов отмечается высокий уровень приверженности собственным традициям и культурным обычаям. Так, более половины респондентов $(59,4 \%)$ соблюдают все традиции и обычаи своего народа - как религиозные, так и светские. Примерно 1/5 опрошенных мигрантов (19,6\%) соблюдают только светские традиции и обычаи. Соблюдение только религиозных традиций характерно для $12,8 \%$ респондентов. Менее $1 / 10$ респондентов $(8,2 \%)$ не соблюдают никакие обычаи своей страны, что подтверждает тезис об особом отношении мигрантов к собственной культурной памяти. Анализ интервью мигрантов показывает, что состояние религиозной инфраструктуры в городах опроса различается. Наибольшее число положительных отзывов о религиозной инфраструктуре приходится на Казань. Это объясняется историческим развитием города как мультикультурного и мультирелигиозного центра.

Анализ отношения мигрантов к традициям и обычаям страны исхода в разрезе возраста показывает, что не соблюдают традиции и обычаи только мигранты в возрасте 40-49 лет (см. табл. 5).

Таблица 5

Соблюдение мигрантами традиций и обычаев своей страны в зависимости от возраста, \%

\begin{tabular}{|l|c|c|c|c|c|c|}
\hline \multirow{2}{*}{$\begin{array}{c}\text { Соблюдаете ли Вы традиции } \\
\text { и обычаи своей родной страны? }\end{array}$} & \multicolumn{6}{|c|}{ Возраст респондента, годы } \\
\cline { 2 - 7 } & $\mathbf{1 8 - 2 4}$ & $\mathbf{2 5 - 2 9}$ & $\mathbf{3 0 - 3 9}$ & $\mathbf{4 0 - 4 9}$ & $\mathbf{5 0 - 5 9}$ & $\mathbf{6 0}$ и старше \\
\hline $\begin{array}{l}\text { Не соблюдаю традиции и обычаи } \\
\text { родной страны }\end{array}$ & - & - & - & 25,0 & - & - \\
\hline $\begin{array}{l}\text { Соблюдаю и светские, и } \\
\text { религиозные традиции и обычаи }\end{array}$ & 100,0 & 70,0 & 93,8 & 75,0 & 100,0 & 100,0 \\
\hline $\begin{array}{l}\text { Соблюдаю только религиозные } \\
\text { традиции и обычаи }\end{array}$ & - & 30,0 & 6,2 & - & - & - \\
\hline
\end{tabular}

Ответы на тот же вопрос в зависимости от длительности проживания показывают, что не соблюдают традиции только незначительная часть мигрантов, проживающих на территории города 6-10 лет (см. табл. 6). 
Таблица 6

\section{Соблюдение мигрантами традиций и обычаев своей страны в зависимости} от длительности проживания, \%

\begin{tabular}{|l|c|c|c|c|c|}
\hline \multirow{2}{*}{$\begin{array}{c}\text { Соблюдаете ли Вы традиции и обычаи } \\
\text { своей родной страны? }\end{array}$} & \multicolumn{5}{|c|}{ Длительность проживания на территории города, } \\
\cline { 2 - 6 } & Мелных лет $\mathbf{1}$ & $\mathbf{1 - 2}$ & $\mathbf{3 - 5}$ & $\mathbf{6 - 1 0}$ & $\mathbf{1 1 - 2 0}$ \\
\hline $\begin{array}{l}\text { Не соблюдаю традиции и обычаи } \\
\text { родной страны }\end{array}$ & - & - & - & 8,3 & - \\
\hline $\begin{array}{l}\text { Соблюдаю и светские, и религиозные } \\
\text { традиции и обычаи }\end{array}$ & 100,0 & 100,0 & 84,6 & 75,0 & 100,0 \\
\hline $\begin{array}{l}\text { Соблюдаю только религиозные } \\
\text { традиции и обычаи }\end{array}$ & - & - & 15,4 & 16,7 & - \\
\hline
\end{tabular}

Обращает на себя внимание факт абсолютно положительного отношения к традициям и обычаям страны исхода как среди мигрантов, проживших в принимающей стране менее 2 лет, так и мигрантов, проживающих в России более 11 лет. Анализ отечественных исследований, посвященных адаптации и интеграции мигрантов, позволяет предположить влияние как минимум двух тенденций. Во-первых, отсутствие интереса к интеграции может быть связано с тем, что мигрант первоначально может воспринимать место пребывания как временное (заработки, получение гражданства, образования). Отечественные исследователи неоднократно указывали на эту существенную проблему российских миграционных процессов [Мукомель 2011: 39]. Во-вторых, отсутствие потребности в культурной интеграции у мигрантов, длительное время проживающих на территории России, связано с устойчивыми связями внутри своего сообщества. На этот факт также неоднократно указывалось в отечественной научной литературе [Дмитриев, Пядухов 2011: 58; Авдеева 2018: 140; Богдан 2014: 90]. В частности, было выявлено, что самих мигрантов, приезжающих в Россию, с точки зрения уровня адаптационных возможностей можно разделить на три группы: наиболее адаптированные (греки, казахи, армяне, азербайджанцы), наименее адаптированные (узбеки, киргизы, таджики), а также группа промежуточной адаптации (украинцы) [Воронова, Воронов 2019: 74].

Не стоит забывать, что вовлеченность мигрантов в практики «своей» и «чужой» праздничной культуры испытывает существенное влияние отношения к ним принимающего общества и его собственного отношения к праздникам. И здесь вслед за многочисленными отечественными исследователями нам приходится констатировать факт существенного кризиса праздничной культуры в России. Данный кризис связан с отсутствием синхронизации различных темпоральностей - дореволюционной, советской, постсоветской. Этому способствует отсутствие системности праздничной культуры, смешение ценностей советского и постсоветского периода, рост консервативных тенденций в обществе. В этой связи не удивительно, что опросы показывают сохранение значительного числа людей «не понимающих» значение новых государственных праздников в России (День России, День народного единства) [Крылова 2015].

Не добавляет оптимизма и ситуация с ростом ксенофобии в российском обществе, а также общая неопределенность миграционной политики, которая, по мнению В.С. Малахова и В.И. Мукомеля, постоянно колеблется между либеральными и консервативными тенденциями [Малахов 2011: 201; Мукомель 2011: 41]. Незавершенность процессов формирования российской гражданской нации продолжает способствовать тому, что «в российских дискурсах о мигран- 
тах их гражданская принадлежность подменяется этническим происхождением; национальность в обыденном сознании превалирует над гражданством» [Мукомель 2011: 37]. Наконец, общим фоном выступают сами социальные проблемы российского общества, что актуализирует поиски социальной справедливости и “фрустрационные состояния" <... мигранты в этом плане представляют собой идеальный объект для смещенной агрессии, особенно в полиэтничных регионах и городах с высоким уровнем социальной дифференциации общества» [Богдан 2014: 91].

Говоря о праздничной культуре как среде межэтнического взаимодействия культурной памяти мигрантов и принимающего общества, мы полностью соглашаемся с позицией В.С. Малахова, неоднократно указывавшего, что успешная культурная интеграция возможна только после эффективной социально-экономической интеграции. Вместе с тем не менее важна сама социально-психологическая атмосфера доверия, где праздник может оказать неоценимую услугу. Было бы ошибкой делать ставку как на однозначное принятие мигрантами российской праздничной культуры, так и на высокий уровень открытости местного населения. Даже такой, казалось бы, символически нейтральный праздник, как День Победы (9 мая), отсылающий к общему советскому прошлому, может выступать не столько фактором консолидации, сколько фактором разобщения в силу существенной трансформации политик памяти в бывших постсоветских республиках в последние три десятилетия.

Однако было бы еще большей ошибкой не делать ставку на праздники как важный инструмент сплочения. Общая память конструируется не только в практиках повседневного общения и труда [Мукомель 2011: 48], но и может не менее эффективно конструироваться в праздничных ритуалах. Вопрос, следовательно, в специфике и направленности корректировки имеющихся праздников и ритуалов. В данном случае в первую очередь необходимо учитывать селективность практик интеграции, о которой говорит В.И. Мукомель. В зависимости от группы мигрантов (соотечественники, иммигранты, гастарбайтеры) смысл и наполнение праздника могут существенно варьироваться. Во-вторых, в силу необходимости формирования гражданской идентичности мигрантов, их включения в российский социум, а не в диаспоры имеет смысл сделать ставку не столько на государственные общероссийские коммеморации, сколько на локальные и региональные праздники, предполагающие большую степень включения коллег, соседей и в меньшей степени содержащих элементы общественного и государственного контроля. В данном случае удачно подходит День города, где речь могла идти о репрезентации взгляда мигрантов на тот населенный пункт/улицу/район, в котором живут они и их семьи. В-третьих, речь могли бы идти о локальных версиях года бывших постсоветских республик в регионах (Год Украины в Липецкой области, Год Таджикистана в Тамбовской области), которые позволяли бы направлять дополнительные общественные и государственные усилия, с одной стороны, на презентацию культуры мигрантов, а с другой - на расширение знаний принимающего общества о культуре, истории и идентичности стран исхода мигрантов. В-четвертых, поскольку оптимальной для России, по мнению исследователей, является «модель этнокультурной самоидентификации при условии принятия мигрантами гражданской российской идентичности» [Воронова, Воронов 2019: 74], важным представляется усиление этнокультурных элементов в содержании общероссийских государственных праздников (День Победы, День России, День народного единства, Новый год). В-пятых, необходима существенная проработка праздников силовых ведомств и армейских подразделений (День ВДВ, День пограничника, День ВМФ, День сил специальных операций), которые ежегодно превраща- 
ются в дополнительный фактор ухудшения межнациональных отношений. В текущей ситуации данная практика скорее является маргинальной и во многом реализуется усилиями отдельных вузов, школ, общественных организаций, что, как правило, недостаточно освещается в местных СМИ.

Предложения, высказанные выше, однако, останутся декларациями без подключения двух важнейших ресурсов, входящих в сферу государственной политики. Речь идет о максимально возможном расширении доступности бесплатного изучения русского языка и литературы для мигрантов и максимально положительной позиции центральных СМИ в отношении миграционной политики и культурной адаптации мигрантов в России. В таком случае взаимодействие культурной памяти может пойти в рамках описанной выше культурной диффузии, даже относительное развитие которой мы рассматриваем как положительный сценарий. В настоящий момент анализ исследований ведущих российских социологов, изучающих проблемы миграции, скорее показывает большую реалистичность нейтрального сценария (сохранение существующего положения) или негативного сценария (дальнейший рост ксенофобии и разобщенности). В этом случае официальные коммеморации в России останутся «праздниками для русских», а попытки власти инициировать коммеморации народного единства будут получать отчетливо националистический след.

Статья подготовлена при финансовой поддержке Российского научного фонда, проект № 17-78-20149 в рамках работы Школымолодогоэтнополитологав Республике Башкортостан.

\section{Список литературы}

Авдеева Ю.Н. 2018. Значение культурной памяти мигрантов для этнической самоидентификации (на материале Красноярского края): дис. ... к.культ. Красноярск. 168 с.

Богдан С.С. 2014. Факторы межэтнической агрессии и насилия во взаимодействии общностей мигрантов и населения. - Вестник Сургутского государственного педагогического университета. № 2(29). С. 85-92.

Бурдье П. 2007. Социология социального пространства. М.: Изд-во Института экспериментальной социологии. С. 87-96.

Воронова М.В., Воронов В.В. 2019. Аналитическая модель факторов адаптации и интеграции мигрантов в регионах России. - Власть. Т. 27. № 6. С. 69-76.

Дмитриев А.В., Мукомель В.И. 2008. Этническая иммиграция: конфликтное измерение. - Россия в глобальных процессах: поиски перспективы. М.: Изд-во ИС РАН. С. 102-118.

Дмитриев А.В., Пядухов Г.А. 2011. Мигранты и социум: интеграционный и дезинтеграционный потенциал практик взаимодействия. - Социс. Социологические исследования. № 12(332). С. 50-59.

Крылова В.Н. 2015. Проблемы и перспективы современной российской праздничной культуры. - Вестник Казанского государственного университета культуры и искусств. № 4-1. С. 43-47.

Малахов В.С. 2011. Культурные различия и политические границы в эпоху глобальных миграций. М.: Новое литературное обозрение. 232 с.

Мукомель В.И. 2011. Интеграция мигрантов: вызов, политика, социальные практики. - Мир России. № 1. С. 34-50.

Шумилова П.А. 2018. Российские праздники как канал интеграции иноэтничных мигрантов из стран Средней Азии в принимающее сообщество. ХХІ Уральские социологические чтения. Социальное пространство и время региона: проблемы устойчивого развития: материалы международной научно-практиче- 
ской конференции. Екатеринбург, 15-16 марта 2018 г. Екатеринбург: Изд-во Гуманитарного университета. С. 399-401.

History, Memory and Migration: Perceptions of the Past and the Politics of Incorporation (ed. by J. Glynn, O. Kleist). 2012. London: Palgrave MacMillan.

Holocaust Memory in a Globalizing World (ed. by J. Eder, Ph. Gassert). 2017. Göttingen: Wallstein Verlag.

Memory and Migration: Multidisciplinary Approaches to Memory Studies (ed. by J. Creet, A. Kitzmann). 2011. Toronto: University of Toronto Press.

Perceptions of the Holocaust in Europe and Muslim Communities: Sources, Comparisons and Educational Challenges (ed. by G. Jikeli, J. Allouche-Benayoun). 2013. Dordrecht: Springer.

BLAGININ Vladislav Sergeevich, Research Associate of the Lipetsk Branch of the Financial University under the Government of the Russian Federation (126 Internatsional'naya St, Lipetsk, Russia, 398050; kibervlad@mail.ru)

LINCHENKO Andrei Aleksandrovich, Cand.Sci. (Philos.), Associate Professor; Research Associate of the Lipetsk Branch of the Financial University under the Government of the Russian Federation (126 Internatsional'naya St, Lipetsk, Russia, 398050; linchenko1@mail.ru)

GOLOVASHINA Oksana Vladimirovna, Cand.Sci. (Hist.), Associate Professor of G.R. Derzhavin Tambov State University (33 Internatsional'naya St, Tambov, Russia, 392000; ovgolovashina@mail.ru)

\title{
FESTIVE COMMEMORATIONS AND SYMBOLIC DATES IN THE MODERN RUSSIAN MIGRATION SOCIETY
}

\begin{abstract}
The article analyzes the results of an empirical study conducted with the support of the Russian Science Foundation in 2018-2019 in the cities of Saratov, Lipetsk, Tambov, Voronezh, Kazan'. The purpose of the work was to study the possibilities of integrating the cultural memory of migrants into the Russian society using the example of commemorative practices related to holiday culture. Using the definition of the holiday proposed by $P$. Bourdieu, the authors understood the holiday as an indicator and an instrument of cultural and historical exchange. Based on the chosen theoretical and methodological framework, an analysis of empirical material showed the following results: 1) migrants generally evaluate Russian holidays positively, but only a third of them take an active part in holiday practices; 2) with aging and an increase in the length of stay, migrants find more opportunities for celebrating religious holidays; 3) most migrants observe the secular and religious customs of the country of origin. The integration of migrants into the Russian holiday culture was hindered by the crisis of the holiday culture itself, the growth of xenophobia and the uncertainty of the politics of migration. To avoid further growth of xenophobia and disunity, the authors suggest taking into account the peculiarities of specific groups of migrants, focusing more on local rather than federal holidays, and expanding migrants' access to the study of the Russian language and culture.
\end{abstract}

Keywords: migrants, cultural memory, holiday commemorations, integration 